\title{
DEMONSTRAÇÕES CONTÁBEIS DOS CLUBES DE FUTEBOL DO CAMPEONATO CATARINENSE DE 2012: VERIFICAÇÃO DA ADEQUAÇÃO À LEGISLAÇÃ̃O VIGENTE
}

\author{
Irineu Afonso Frey ${ }^{1}$ \\ Robson Zaia da Cunha \\ ${ }^{1}$ Universidade Federal de Santa Catarina \\ Irineu.frey@ufsc.com, robzaia@gmail.com
}

\section{Resumo}

As entidades desportivas, após a promulgação da Lei 9.615/1998, conhecida como Lei Pelé, passaram a ser reguladas pelas leis de mercado com as mesmas obrigações das demais empresas privadas. Em 2004, por meio da resolução 1.005, o Conselho Federal de Contabilidade (CFC) aprovou a NBC T 10.13 para estabelecer critérios e procedimentos específicos de avaliação e de registros contábeis e também para a estruturação das demonstrações contábeis das entidades de futebol profissional e demais práticas desportivas profissionais. Este estudo teve por objetivo verificar se as Demonstrações Contábeis dos clubes integrantes do Campeonato Catarinense de 2012 apresentavam-se de acordo com a legislação contábil vigente. Para isso, esta pesquisa teve caráter exploratório-documental, pois observou, analisou e comparou os elementos da pesquisa. Para alcançar o resultado esse estudo utilizou as demonstrações publicadas pelos clubes e o modelo de análise adaptado de Souza (2013), com 12 itens abordados na norma NBC T 10.13, sendo realizado em seis clubes que apresentaram suas demonstrações relativas ao ano de 2012, que são: Avaí, Criciúma, Hermann Aichinger, Figueirense, Joinville e Metropolitano. Concluiuse que, enquanto há clubes próximos do atendimento às exigências da norma, há outros que estão distantes de cumpri-la, sendo necessário mais atenção e responsabilidade dos gestores esportivos desses clubes, principalmente dos profissionais responsáveis pela contabilidade. Conclui-se também que os clubes catarinenses estão dentro da média nacional em relação à comparação realizada com o estudo de Souza (2013).

Palavras-chave: Futebol, Demonstrações Contábeis, Normatização.

\section{DEMONSTRAÇÕES CONTÁBEIS DOS CLUBES DE FUTEBOL DO CAMPEONATO CATARINENSE DE 2012: VERIFICAÇÃO DA ADEQUAÇÃO À LEGISLAÇÃ̃ VIGENTE}

\begin{abstract}
After the promulgation of Law 9.615 / 1998, known as Pelé Law, the sports bodies have been regulated by market laws with the same duties as other private companies. In 2004, through the NBC T 10:13 in resolution 1.005, the Federal Accounting order to establish specific Council(CFC) approved criteria and assessment procedures concerning evaluation and accounting records and also concerning the structure offinancial statements of professional football entities and other professional sports practices. This study aimed to verify whether the financial statements of the clubs of Santa Catarina Football Championship 2012 were presented in accordance with current accounting legislation. To this end, this research had an exploratory-documentary character, therefore the research elements were observed, analyzed and compared. To achieve the result, this study used the statements published by the clubs and the analysis model adapted from Souza (2013), with 12 items covered in the norm NBC 10:13 T, being held in six clubs that
\end{abstract}

R. Eletr. do Alto Vale do Itajaí - REAVI, v. 3, n. 4, p. 012- 024, dez., 2014.

ISSN 2316-4190, DOI: 10.5965/2316419003042014012 


presented theirstatements concerning the year of 2012, which

are: Avai, Criciúma, Hermann Aichinger, Figueirense, Joinville and Metropolitano. It was concluded that, while there are clubs close to conformity to the norm requirements, there are others that are behind this compliance, requiring more attention and responsibility of sports managers, especially for professionals responsible for accounting. It was also concluded that Santa Catarina clubs are within the national average in relation to the comparison made with the study of Souza (2013).

Keywords: Football, Financial Statements, Normatization.

\section{Introdução}

Após a promulgação da Lei 9.615, de 24 de Março de 1998, conhecida popularmente como a Lei Pelé, e a consequente mudança trazida para as entidades desportivas de futebol que passaram então, a serem reguladas pelas leis de mercado com as mesmas obrigações das demais empresas privadas, os clubes de futebol passaram a buscar uma conformidade com a legislação vigente.

A partir da obrigatoriedade da apresentação das Demonstrações Contábeis de acordo com o artigo 47 Lei 9.615/98, o Conselho Federal de Contabilidade (CFC) por meio da resolução 1005/04, aprovou uma norma para estabelecer critérios e procedimentos com o objetivo de dar uma diretriz para as entidades de prática desportiva do país, a NBC T 10.13 (NORMAS BRASILEIRAS DE CONTABILIDADE, 2013).

Com isso, os clubes de futebol devem apresentar suas Demonstrações Contábeis nos termos da lei e de acordo com os padrões e critérios estabelecidos pelo Conselho Federal de Contabilidade (CFC), até o último dia útil do mês de abril do ano subsequente (LEI 9.615, 1998). A divulgação das demonstrações contábeis pelos clubes de futebol tem o intuito de dar transparência da gestão destas entidades.

Além da observância da legislação vigente pelos clubes do Campeonato Catarinense 2012, destaca-se que é responsabilidade dos profissionais da contabilidade destes clubes cumprir integralmente o que determina a legislação sobre a elaboração e publicidade das Demonstrações Contábeis.

Diante disso, apresenta-se a seguinte pergunta de pesquisa: as Demonstrações Contábeis apresentadas pelos clubes que integram o Campeonato Catarinense de 2012 estão de acordo com a legislação contábil vigente? Como objetivo foi definido: Verificar se as Demonstrações Contábeis dos clubes integrantes do Campeonato Catarinense 2012 estão de acordo com a legislação contábil vigente.

O estudo está estruturado em cinco seções sendo a primeira esta introdução, posteriormente a fundamentação teórica que sustenta o estudo, seguido pela metodologia utilizada para a realização da pesquisa. A seção quatro apresenta, de forma detalhada, o estudo realizado, seguido pelas considerações finais e recomendações. Por último, as referências citadas no decorrer do estudo realizado.

\section{Fundamentação Teórica}

A fundamentação teórica apresentada discorre sobre os seguintes temas: Legislações Vigentes, Normas Brasileiras Contabilidade dos Aspectos Contábeis Específicos em Entidades Desportivas Profissionais - NBC T 10.13 e Resolução 1005/04, NBC Interpretação Técnica Geral 2003 e Resolução 1.429/2013.

\subsection{Legislação Desportiva}


Em 1998 foi promulgada a Lei 9.615 pelo Presidente Fernando Henrique Cardoso, a qual aprimorou a Lei $8.672 / 93$, conhecida como Lei Zico. Um dos pontos principais pontos foi a revogação da Lei 6.354/76, conhecida como Lei do Passe, que até então conduzia as relações entre os atletas profissionais e os clubes esportivos. De acordo com o artigo 11, da Lei 6.354/1976 "entende-se por passe a importância devida por um empregador a outro pela cessão do atleta durante a vigência do contrato ou depois de seu término, observadas as normas desportivas pertinentes".

Dessa forma, os clubes detinham amplos direitos sobre o passe dos atletas profissionais até a chegada dessa nova Lei. Com a promulgação, em 1998 da Lei 9.615 e de suas alterações e aprimoramentos no decorrer dos anos, o vínculo entre atletas profissionais e os clubes ficaram limitados a contratos trabalhistas, contendo penas para algumas situações, conforme o artigo 28 da Lei 12.395/2011.

A Lei Pelé também estabeleceu regras com relação aos atletas formados nas categorias de base dos clubes formadores, dando direito a estes a assinatura do primeiro contrato especial de trabalho desportivo dos atletas. O parágrafo segundo do artigo 28 da Lei 12.935/2011 define clube formador. Outro aspecto arrolado no artigo 28 é relacionado ao auxílio financeiro que a entidade desportiva pode repassar aos atletas em formação sob a forma de bolsa aprendizagem, sem que com isso seja gerado vínculo empregatício entre as partes.

Caso o clube formador do atleta não possa assinar o primeiro contrato de trabalho por oposição do atleta ou quando este vincular-se à outra entidade de prática desportiva, o clube fará jus ao valor indenizatório (LEI 9.615/98, ARTIGO 28).

Outro ponto importante na Lei foi a mudança ocorrida com relação as obrigações e responsabilidades, na qual os clubes de futebol profissional passam a ser regulados pelas leis do mercado. Na visão de Proni (2000, p. 200), referente a essa mudança:

\begin{abstract}
ao prescrever que as atividades relacionadas a competições de atletas profissionais seriam privativas de entidades constituidas sob a forma de sociedade comercial, na prática a legislação não dava muita escolha: ou os clubes de futebol se transformariam em empresas, ou passariam a gerir o departamento profissional nos moldes estabelecidos pelo Código Comercial (ficando sujeitos a pagar os impostos de praxe e até a ter sua falência requerida), ou deixariam de participar de torneios profissionais.
\end{abstract}

Especificamente sobre os administradores das entidades desportivas profissionais, a redação da Lei 12.395 de 2011 também esclarece que os mesmos respondem solidariamente e ilimitadamente pelos atos ilícitos praticados nos termos do Código Civil (LEI 9.615, 1998). Ainda no artigo 27, para a obtenção de recursos de financiamento com recursos públicos ou recuperação econômico-financeira a lei também impõe algumas condições aos clubes de futebol profissional, como a de apresentar suas Demonstrações Contábeis juntamente com os respectivos relatórios de auditoria, além de apresentar um modelo profissional e transparente (LEI 9.615, 1998).

Com relação às Demonstrações Contábeis, os clubes também passaram a ter a obrigação nos termos da lei e de acordo com os padrões e critérios estabelecidos pelo Conselho Federal de Contabilidade, de publicar as suas Demonstrações Contábeis até o último dia útil do mês de abril do ano subsequente (LEI 9.615,1998).

O artigo 46-A que trata dessa obrigatoriedade foi incluído na Lei 9.615/1998 por meio da Lei 10.672/2003, porém, a obrigatoriedade da apresentação das Demonstrações Contábeis nos sítios eletrônicos dos próprios clubes e nas federações a que estiverem associados veio com a redação da Lei 12.395 de 2011.

O Conselho Federal de Contabilidade, em 17 de setembro de 2004, por meio da Resolução ${ }^{\circ}$ $1.005 / 2004$, aprovou a NBC T 10.13 que trata dos aspectos contábeis especificamente voltados para as Entidades Desportivas Profissionais. 


\subsection{Normas Brasileiras de Contabilidade dos Aspectos Contábeis Específicos em Entidades Desportivas Profissionais - NBC T 10.13}

As Normas Brasileiras de Contabilidade, por meio da NCB T 10.13, aprovada por meio da resolução 1005/04 do CFC, estabelecem critérios e procedimentos específicos de avaliação, de registros contábeis e de estruturação das demonstrações contábeis das entidades de futebol profissional e demais práticas desportivas profissionais, as quais também são aplicadas às confederações, federações, clubes, ligas, sindicatos, associações, entidades controladas, coligadas e outras que, direta ou indiretamente, estejam ligadas à exploração da atividade desportiva profissional (NORMAS BRASILEIRAS DE CONTABILIDADE, 2013).

Ainda conforme as Normas Brasileiras de Contabilidade (2013), a NBC T 10.13, aplicam-se às entidades desportivas profissionais os Princípios da Contabilidade, bem como as Normas Brasileiras de Contabilidade, suas interpretações e comunicados técnicos, editados pelo Conselho Federal de Contabilidade.

Com relação aos registros contábeis, a NBC T 10.13 (2013) esclarece que devem "evidenciar as contas de receitas, custos e despesas, segregando o desporto profissional das demais receitas esportivas, recreativas ou sociais, e serem efetuados de acordo com os Princípios de Contabilidade, em especial, o da Competência e o da Oportunidade".

A mesma norma também aborda de maneira específica o registro dos gastos com os atletas de categoria de base em formação, os quais devem estar suportados, no mínimo, pelos seguintes controles:

a) Composição dos gastos diretamente relacionados com a formação do atleta com base mensal e regime de competência, por tipo (alojamento, alimentação, transporte, educação, vestuário, comissão técnica, etc.);

b) Composição dos gastos diretamente relacionados com a formação do atleta com base mensal e regime de competência, por categoria (infantil, juvenil, juniores).

c) Composição do elenco por categoria e registros auxiliares que demonstrem controle de cada categoria e que permitam a apuração de gastos por atleta;

d) Relatório mensal de apropriação de gastos para o resultado e para o imobilizado.(NBC T 10.13, 2013).

Quanto às Demonstrações Contábeis, a NBC T 10.13 explica que devem ser preparadas de acordo com a NBC T 3 - Conceito, Conteúdo, Estrutura e Nomenclatura e acolher as disposições específicas das Normas Brasileiras de Contabilidade quanto à nomenclatura das contas (NBC T $10.13,2013)$.

\subsection{Normas Brasileiras de Contabilidade - Interpretação Técnica Geral 2003 - Entidade Desportiva Profissional}

A NBC - Interpretação Técnica Geral 2003 para entidades desportivas profissionais, foi aprovada pela Resolução CFC n 1.429 em 25 de janeiro de 2013 e tem como objetivo estabelecer critérios e procedimentos específicos de avaliação, de registros contábeis e de estruturação das demonstrações contábeis das entidades de futebol profissional e demais entidades desportivas profissionais (RESOLUÇÃO CFC N $\left.\mathrm{N}^{\circ} 1.429,2013\right)$. Esta resolução alterou algumas interpretações da norma NBC T 10.13, sendo a principal referente à classificação dos valores gastos com os atletas em formação. Na resolução que foi revogada, o mesmo deveria ser registrado no Ativo Imobilizado e na norma NBC ITG 2003 passou a ser registrado no Ativo Intangível da entidade desportiva.

Além do registro dos valores gastos com os atletas em formação, a entidade também deve registrar a aquisição e renovação dos contratos dos atletas, incluindo luvas, desde que sejam 
esperados benefícios econômicos atribuíveis a este ativo e os custos possam ser mensurados com confiabilidade. Os valores que não tiverem relacionados com a formação do atleta devem ser registrados diretamente nas despesas (NBC ITG 2003, 2013).

Ainda de acordo com a NBC ITG 2003, quando da ocasião em que for realizada a assinatura do contrato profissional dos atletas em formação, os valores gastos registrados na contabilidade no Ativo Intangível deverão ser reclassificados para Atletas Formados, que devem ser amortizados de acordo com o período do contrato.

Em relação ao controle dos gastos com formação de atletas, a NBC ITG 2003 esclarece que tal controle deve ser suportado pela composição dos gastos diretamente relacionados com a formação de cada atleta com base mensal e pelo regime de competência, dividido em 3 (três) categorias sendo a infantil, a juvenil e a júnior. Os valores gastos também devem ser repartidos em tipos, sendo de alojamento, alimentação, transporte, educação, vestuário, comissão técnica, entre outros.

As receitas de bilheteria, direito de transmissão e de imagem, patrocínio, publicidade, luvas e outras assemelhadas, de acordo com a ITG 2003, devem registradas em contas específicas, conforme o princípio da competência e quando forem recebidas antecipadamente, no Passivo Circulante se forem de curto prazo e no Passivo não Circulante quando forem de longo prazo, dependendo apenas do prazo de realização da receita.

Sobre as Demonstrações Contábeis, a ITG 2003 obriga que os clubes apresentem o Balanço Patrimonial, a Demonstração do Resultado, a Demonstração do Resultado Abrangente, a Demonstração das Mutações do Patrimônio Liquido, a Demonstração dos Fluxos de Caixa e as Notas Explicativas.

Um estudo similar foi realizado por Souza (2013) considerando dados em nível nacional, limitado aos 40 clubes participantes da Série A e B do Campeonato Brasileiro de 2011. Desse total, foram estudados 24 clubes com as maiores receitas, de acordo com os balanços publicados no referido ano. O autor buscou analisar o nível de evidenciação das Demonstrações Contábeis apresentadas pelos clubes, fazendo uma análise por Estado, bem como averiguar o grau de conformidade das Demonstrações Contábeis com a legislação vigente.

O resultado apresentado pelo autor destacou o clube São Paulo Futebol Clube com um nível de apresentação das Demonstrações Contábeis atingindo uma nota de 83,33 no grau de conformidade com a legislação vigente, ficando em $1^{\circ}$ lugar na análise realizada. Os clubes com os piores resultados foram o Esporte Clube Bahia e a Associação Atlética Ponte Preta, ambos com apenas $25 \%$ de conformidade à norma NBC T 10.13.(SOUZA, 2013).

A pesquisa também realizou uma análise em nível regional, sendo que os melhores resultados apresentados foram para a região Sul e Sudeste do país, considerando que dos vinte e quatro clubes pesquisados, vinte estão concentrados nessas duas regiões e obtiveram uma média de 62,50 e 52,38, respectivamente de conformidade. (SOUZA, 2013).

$\mathrm{Na}$ região Nordeste, com apenas três clubes integrantes, o resultado foi o pior, com média de 36,11 de conformidade à norma NBC T 10.13. Dessa maneira Souza (2013, p. 54) conclui que "não há uma homogeneidade significativa entre os clubes de uma mesma região, ressalvando-se a região nordeste, onde todos os clubes ficaram aquém das expectativas". Para este estudo não foram considerados estudos similares que tratassem do Campeonato Catarinense.

\section{Metodologia}

Esta pesquisa tem caráter exploratório-documental, pois são utilizadas informações já apresentadas pelos clubes de futebol, sem alterações, realizando simplesmente a interpretação e análise dos dados coletados.

Esta pesquisa limitou-se aos clubes que participaram do Campeonato Catarinense de 2012, sendo ao todo dez clubes que integraram tal competição, os quais são: Figueirense Futebol Clube; Avaí Futebol Clube, Associação Chapecoense de Futebol; Clube Náutico Marcílio Dias; 
Criciúma Esporte Clube; Joinville Esporte Clube; Clube Atlético Metropolitano; Camboriú Futebol Clube; Brusque Futebol Clube e Clube Atlético Hermann Aichinger. A busca por informações também limitou-se às Demonstrações Contábeis publicadas no sítio da Federação Catarinense de Futebol e do sítio dos próprios clubes que integraram a competição.

Foram encontradas publicações das Demonstrações Contábeis, no sítio da Federação Catarinense de Futebol, de seis clubes que participaram da competição em 2012, sendo eles: Figueirense Futebol Clube; Avaí Futebol Clube; Criciúma Esporte Clube; Joinville Esporte Clube; Clube Atlético Metropolitano e Clube Atlético Hermann Aichinger. Os outros quatro clubes foram pesquisados em seus respectivos sítios eletrônicos e as demonstrações não foram localizadas. Os quatro clubes foram: Associação Chapecoense de Futebol; Clube Náutico Marcílio Dias; Camboriú Futebol Clube e Brusque Futebol Clube, sendo que o último está com seu sítio em manutenção.

Dessa forma, foi realizada uma tentativa via correio eletrônico, sem obter-se sucesso. Por último, foi feita solicitação via telefone para os clubes, a qual também não teve retorno, impossibilitando que a verificação fosse realizada nos dez clubes participantes do campeonato.

Dos dez clubes que integraram a competição catarinense em 2012, somente seis estão com suas respectivas Demonstrações Contábeis publicadas no sítio eletrônico da Federação Catarinense de Futebol, sendo que os demais clubes descumprem a Lei 12.395 de 2011, a qual acrescentou à Lei 9.615 de 1998 a obrigatoriedade da publicação em sítio eletrônico próprio e da respectiva entidade de administração a que estiver associado (LEI 9.615, 1998).

A verificação da aderência das informações prestadas nas demonstrações com o requerido pela normatização vigente foi realizada com base no modelo adotado por Souza (2013). Por fim, foram confrontados os resultados obtidos da verificação entre os clubes integrantes do Campeonato Catarinense de 2012, ou seja, em nível estadual, com os resultados obtidos da análise realizada por Souza (2013), que teve uma abordagem em nível nacional dos 24 clubes com maiores receitas do futebol brasileiro em 2011, além das considerações e sugestões finais para próximas pesquisas nessa área.

\section{Apresentação e Discussão dos Resultados}

A apresentação e a discussão dos resultados foi divida em dois momentos: Verificação da adequação à legislação e Comparação em nível nacional, de acordo com o estudo de Souza (2013).

\subsection{Verificação da conformidade com a legislação}

Dessa forma, foram utilizados 12 itens com base na norma NBC $\mathrm{T} 10.13$, sendo esses itens adaptados com base na norma mais atualizada. A análise foi realizada tomando por base as Demonstrações Contábeis disponibilizadas em sítios eletrônicos. Para otimizar a visualização foi elaborado o Quadro 01 que apresenta o desempenho dos clubes nos itens avaliados.

Quadro 01: Conformidade com a NBC T 10.13

\begin{tabular}{|l|c|c|c|c|c|c|c|}
\hline \multicolumn{1}{|c|}{ ITENS ANALISADOS/CLUBES } & & & & & & \\
& & & & & & \\
\hline $\begin{array}{l}\text { Registro no Ativo Imobilizado ou Ativo Intangível dos } \\
\text { Valores gastos com a formação de Atletas }\end{array}$ & SIM & NÃO & NÃO & SIM & SIM & NÃO & $50,00 \%$ \\
\hline Registro no Ativo Imobilizado ou Ativo Intangível dos & SIM & NÃO & NÃO & SIM & SIM & NÃO & $50,00 \%$ \\
\hline
\end{tabular}




\begin{tabular}{|c|c|c|c|c|c|c|c|}
\hline $\begin{array}{l}\text { valores gastos com a contratação ou a renovação de } \\
\text { contrato de atletas profissionais, pelo valor pago ou } \\
\text { incorrido. }\end{array}$ & & & & & & & \\
\hline $\begin{array}{l}\text { Registro em contas do resultado operacional das receitas } \\
\text { de bilheteria, direito de transmissão e de imagem, } \\
\text { patrocínio, publicidade e outras assemelhadas. }\end{array}$ & SIM & NÃO & NÃO & SIM & SIM & SIM & $66,67 \%$ \\
\hline $\begin{array}{l}\text { Segregação na DRE das receitas, dos custos e das } \\
\text { despesas de atividades profissionais das demais atividades }\end{array}$ & SIM & NÃO & NÃO & SIM & NÃO & SIM & $50,00 \%$ \\
\hline $\begin{array}{l}\text { Apresentação nas notas explicativas sobre os valores } \\
\text { gastos com formação de atletas registrados no Ativo } \\
\text { Imobilizado ou Ativo Intangível e o montante baixado } \\
\text { para o resultado do exercício. }\end{array}$ & SIM & NÃO & NÃO & SIM & SIM & NÃO & $50,00 \%$ \\
\hline $\begin{array}{l}\text { Apresentação nas notas explicativas sobre a composição } \\
\text { dos direitos sobre os atletas profissionais registrados no } \\
\text { Ativo Imobilizado ou Ativo Intangível, segregando o } \\
\text { valor correspondente ao custo, à amortização e ao prazo } \\
\text { médio remanescente a amortizar. }\end{array}$ & SIM & NÃO & NÃO & SIM & SIM & NÃO & $50,00 \%$ \\
\hline $\begin{array}{l}\text { Apresentação nas notas explicativas sobre as receitas } \\
\text { obtidas e seu correspondente custo de aquisição com a } \\
\text { negociação e a liberação de atletas profissionais. }\end{array}$ & SIM & NÃO & NÃO & SIM & SIM & SIM & $66,67 \%$ \\
\hline $\begin{array}{l}\text { Apresentação nas notas explicativas sobre a composição } \\
\text { do valor das receitas, custos e despesas relevantes por } \\
\text { tipos, quando não evidenciadas na demonstração de } \\
\text { resultado. }\end{array}$ & SIM & NÃO & NÃO & SIM & SIM & SIM & $66,67 \%$ \\
\hline $\begin{array}{l}\text { Apresentação nas notas explicativas sobre as } \\
\text { contingências ativas e passivas de natureza tributária, } \\
\text { previdenciárias, trabalhista e cível. }\end{array}$ & SIM & NÃO & NÃO & SIM & SIM & SIM & $66,67 \%$ \\
\hline $\begin{array}{l}\text { Apresentação nas notas explicativas sobre os seguros } \\
\text { contratados para os atletas profissionais e demais ativos } \\
\text { da entidade. }\end{array}$ & SIM & NÃO & NÃO & SIM & SIM & NÃO & $50,00 \%$ \\
\hline
\end{tabular}

\section{Fonte: Dados da pesquisa (2013).}

O Joinville Esporte Clube demonstrou os valores gastos com a formação do atleta dentro do grupo de Investimentos sem a possibilidade de acesso às Notas Explicativas do clube, impossibilitando a verificação do entendimento para o registro em tal grupo.

Os Clubes Atlético Hermann Aichinger e Metropolitano não evidenciaram no Balanço Patrimonial os valores gastos com atletas em formação e, sem a apresentação de Notas Explicativas a busca por informações na composição do Ativo não Circulante dos referidos clubes foi prejudicada, considerando-se dessa forma, a não conformidade com a legislação.

Quanto ao registro dos valores gastos com a contratação ou renovação dos contratos de Atletas Profissionais, o resultado obtido foi o que o Avaí, Criciúma e Figueirense apresentaramse em conformidade à Legislação, ao contrário de Joinville, Metropolitano e Hermann Aichinger, que, com as demonstrações apresentadas e ausência de Notas explicativas, foram consideradas em não conformidade à norma.

Observa-se uma melhora nos clubes que estão de acordo com a legislação para esse item, isso porque o Joinville, mesmo não apresentando as Notas Explicativas, evidencia na Demonstração do Resultado do Exercício os registros solicitados pela legislação.

O Figueirense, por exemplo, optou por apresentar a segregação das contas de receita operacional nas Notas Explicativas, deixando apenas a Receita Líquida na Demonstração do Resultado do Exercício, motivo esse que levou o clube a ser considerado em conformidade com a legislação.

Os clubes que se encontram em conformidade com a legislação são o Avaí, Criciúma e Joinville. O destaque é o Avaí, que é o clube dos seis analisados que mais segrega as receitas, despesas e custos na apresentação da sua Demonstração do Resultado do Exercício. Entre os clubes que não estão em conformidade com a legislação, está o Figueirense que não apresenta as 
receitas segregadas na Demonstração do Resultado do Exercício, apesar de evidenciar a segregação das despesas e custos.

Observou-se que na Demonstração do Resultado do Exercício do Figueirense faltou maior segregação das receitas obtidas, e apesar de apresentar uma nota segregando as contas dentro das Notas Explicativas, o clube não está de acordo com a norma que estabelece que seja segregada também na demonstração.Com relação à baixa dos valores gastos com formação de atletas percebeu-se que o Avaí, o Criciúma e o Figueirense seguem em conformidade com a legislação. Os demais não publicaram suas Notas Explicativas, e por essa razão, foram considerados em não conformidade.

$\mathrm{Na}$ análise relativa à segregação dos direitos sobre atletas profissionais, constatou-se que o Avaí, Criciúma e Figueirense apresentaram em suas respectivas Notas Explicativas a composição dos direitos sobre atletas profissionais, apesar de não informarem o prazo médio remanescente dos direitos sobre tais atletas. O Figueirense, nesse ponto, é um dos clubes que está em conformidade com a legislação, visto que pelo descrito na Nota Explicativa pode-se perceber que a amortização dos direitos vinculados aos atletas profissionais varia de acordo com o tempo de vigência dos contratos.

Os clubes catarinenses apresentam as receitas obtidas com transações de atletas, porém, sem especificar quais atletas, o que prejudica na interpretação da composição dessas receitas. O Avaí, Criciúma e Joinville, por optarem por apresentar na Demonstração do Resultado do Exercício, também foram considerados em conformidade, apesar de não apresentarem a composição dessas transações efetuadas em 2012, assim como o Figueirense. É importante ressaltar que os clubes precisam aprimorar as informações publicadas, não somente informando o saldo final da conta, mas também aproveitando as Notas Explicativas para evidenciar sua composição.

Observou-se que quatro dos seis clubes analisados no item Segregação das receitas, custos e despesa estão em conformidade com a legislação. Todos apresentaram já na Demonstração do Resultado do Exercício as receitas, despesas e custos segregados para cada tipo. O Figueirense, dos quatro clubes, é o único que utilizou as Notas Explicativas para segregar as suas receitas do ano de 2012. Os demais clubes, Criciúma e Joinville, também apresentam suas receitas, despesas e custos segregados na Demonstração do Resultado do Exercício, sem utilizar as Notas Explicativas para tal finalidade.

Identificou-se que novamente os quatro clubes, Avaí, Criciúma, Figueirense e Joinville, estão em conformidade com a legislação. Os clubes Hermann Aichinger e Metropolitano não apresentaram tais dados nos respectivos Balanços Patrimoniais, da mesma forma como não apresentaram as Notas Explicativas, e foram considerados, portanto, em não conformidade com a legislação. O Joinville, por apresentar no Balanço Patrimonial, foi considerado em conformidade.

$\mathrm{Na}$ análise relacionada à cobertura de seguros, três clubes demonstraram resultado positivo com relação à apresentação dos seguros contratados para atletas profissionais. Apesar de não evidenciarem os atletas e os valores segurados, todos mencionaram com uma nota dentro das respectivas Notas Explicativas os seguros contratados.

\subsection{Comparação dos resultado em nível nacional}

Após a apresentação dos 12 itens verificados obtém-se o resultado final da análise realizada com os clubes catarinenses pesquisados nessa avaliação, conforme evidenciado na Tabela 01.

Tabela 01: Grau de conformidade dos clubes

\begin{tabular}{ccc}
\hline Posição & Clube & Nota (pontos) \\
$1^{\text {o }}$ & Avaí & 90,91 \\
$1^{\text {o }}$ & Criciúma & 90,91 \\
\hline
\end{tabular}




\begin{tabular}{cccc}
\hline $3^{\circ}$ & Figueirense & 81,82 \\
$4^{\mathrm{o}}$ & Joinville & 45,45 \\
$5^{\mathrm{o}}$ & Hermann Aichinger & 0,00 & 0,00 \\
$5^{\mathrm{o}}$ & Metropolitano & $\mathbf{5 1 , 5 2}$ \\
& Média & \\
\hline
\end{tabular}

Fonte: Dados da pesquisa (2013)

Ao verificar as notas e a média apresentada pelos clubes que participaram do Campeonato Catarinense de 2012 percebe-se que há uma discrepância entre os clubes catarinenses: enquanto três clubes destacam-se, outros três demonstram que estão muito aquém de serem considerados aderentes à legislação atual. Nessa avaliação, os clubes com melhor desempenho foram o Criciúma Futebol Clube e Avaí Futebol Clube, ambos com 90,91\% de aproveitamento, sendo os que estão mais próximos de estar em conformidade com a legislação.

Destaque negativo para os dois clubes, Hermann Aichinger e Metropolitano, que na avaliação dos 12 itens constantes na norma NBC T 10.13, em nenhuma delas estiveram em conformidade, o que demonstra descaso e prejudica a credibilidade e transparência das Demonstrações publicadas. Esses dois clubes precisam rever os procedimentos e práticas contábeis adotadas para se adequarem à legislação vigente.

O Joinville, por não publicar as Notas Explicativas, teve sua avaliação prejudicada. A administração deve buscar apresentar todas as informações necessárias ao esclarecimento das demonstrações publicadas. A Nota Explicativa é essencial como fonte complementar e elucidativa.

O Figueirense Futebol Clube, o terceiro melhor posicionado, com $81,82 \%$ de aproveitamento, está próximo da conformidade à legislação vigente, necessitando apenas de alguns ajustes para estar em plena conformidade.

Dois itens dos doze abordados nesta pesquisa não foram apresentados por nenhum dos clubes. Tanto o Balanço Patrimonial segregando as atividades desportivas profissionais das demais atividades, como também o item relacionado com valores em moeda estrangeira de direitos e obrigações com o mercado externo. No primeiro item não se observou a segregação em nenhum dos Balanços Patrimoniais apresentados pelos clubes. Já o segundo item, foi desconsiderado da avaliação por não ser possível identificar que tal situação tenha ocorrido nos clubes analisados.

A média alcançada da análise geral dos clubes a nível estadual ficou em 51,52\%, mostrandose mediano e necessitando uma revisão por parte dos clubes catarinenses para buscarem a adequação às legislações vigentes.

A Tabela 02 apresenta o resultado obtido em nível nacional, pela pesquisa realizada por Souza (2013), o qual reuniu os 24 clubes brasileiros com maior receita em 2011.

Tabela 02: Grau de conformidade dos clubes

\begin{tabular}{cccccc}
\hline & Clube & Nota & Posição & Clube & Nota \\
$1^{\circ}$ & São Paulo & 83,33 & $12^{\circ}$ & São Caetano & 50,00 \\
$2^{\circ}$ & Botafogo & 75,00 & $12^{\circ}$ & Vitória & 50,00 \\
$2^{\circ}$ & Corinthians & 75,00 & $15^{\circ}$ & Goiás & 41,67 \\
$2^{\circ}$ & Grêmio & 75,00 & $15^{\circ}$ & Atlético - PR & 41,67 \\
$5^{\circ}$ & Avaí & 66,67 & $15^{\circ}$ & Portuguesa & 41,67 \\
$5^{\circ}$ & Coritiba & 66,67 & $18^{\circ}$ & Barueri & 33,33 \\
$5^{\circ}$ & Fluminense & 66,67 & $18^{\circ}$ & Cruzeiro & 33,33 \\
$5^{\circ}$ & Internacional & 66,67 & $18^{\circ}$ & Flamengo & 33,33 \\
$5^{\circ}$ & Palmeiras & 66,67 & $18^{\circ}$ & Náutico & 33,33 \\
\hline
\end{tabular}




\begin{tabular}{cccccc}
\hline $5^{\circ}$ & Santos & 66,67 & $18^{\circ}$ & Vasco & 33,33 \\
$11^{\circ}$ & Figueirense & 58,33 & $23^{\circ}$ & Bahia & 25,00 \\
$12^{\circ}$ & Atlético - MG & 50,00 & $23^{\circ}$ & Ponte Preta & 25,00 \\
& & MÉDIA & & $\mathbf{5 2 , 4 3}$ \\
\hline
\end{tabular}

Fonte: Souza (2013, p. 54).

Constata-se que a média obtida em nível nacional foi quase igual à média catarinense, sendo que a primeira ficou com $52,43 \%$ em conformidade com a legislação, enquanto a média em nível estadual ficou em $51,52 \%$.

Dos clubes catarinenses que participaram da pesquisa no estudo de Souza (2013) em 2011, tanto Avaí como o Figueirense evoluíram em relação às notas obtidas na pesquisa realizada em 2012, alcançando $90,91 \%$ e $81,82 \%$ respectivamente, contra $66,67 \%$ e $58,33 \%$ alcançados em 2011, demonstrando um considerável aprimoramento dos dois clubes entre os períodos abordados nos dois estudos.

No caso do Avaí Futebol Clube, em 2011 o clube obteve resultado negativo em relação ao item de segregação das receitas, os custos, e as despesas de atividades profissionais das demais atividades na Demonstração do Resultado do Exercício, e do item relacionado à apresentação das contingências ativas e passivas de natureza tributária, previdenciária, trabalhista e cível nas Notas Explicativas. Em 2012, o resultado obtido foi positivo, de acordo com a verificação realizada nas Demonstrações Contábeis publicadas pelo clube nos sítios da Federação Catarinense de Futebol e do próprio clube, fazendo com que sua nota tivesse a melhora apresentada nesse estudo.

Com relação ao Figueirense Futebol Clube, a mudança no resultado deu-se em outros dois itens constantes na análise, ambos referentes às informações contidas nas Notas Explicativas. $\mathrm{O}$ primeiro relacionado à apresentação dos direitos sobre os atletas profissionais registrados no Ativo Imobilizado ou Ativo Intangível, e o segundo relacionado aos seguros contratados. Em 2012 o clube obteve resultado positivo nos dois itens mencionados.

Com a aprovação da NBC ITG 2003, substituindo a NBC T 10.13, a partir do exercício de 2013, a quantidade de demonstrações apresentadas será maior e outras exigências passarão a valer, dessa forma, será necessário mais responsabilidade por parte dos clubes e dos profissionais da contabilidade na elaboração e apresentação das suas Demonstrações Contábeis, a fim de evitar penalidades previstas na Lei 9.615 de 1998.

\section{Considerações Finais}

Com o Advento da Lei 9.615 de 1998, o futebol brasileiro passou a ser visto e regulado pelas Leis de mercado, com novas exigências e responsabilidades para os clubes de futebol. $\mathrm{O}$ Conselho Federal de Contabilidade, por meio da resolução 1.005 de 2004, aprovou a norma NBC T 10.13 para padronizar e estruturar a elaboração e apresentação das Demonstrações Contábeis para os clubes de futebol.

Pode-se concluir que os clubes catarinenses estão entre a média nacional em relação às exigências estabelecidas pela norma NBC T 10.13, ficando com uma média de 51,82\%, sendo o Criciúma e o Avaí os melhores entre os Catarinenses possuindo 90,91\% de conformidade com a legislação. Os clubes Hermann Aichinger e Metropolitano foram os piores, não alcançando nota em nenhum dos doze itens avaliados.

Com base em uma avaliação individualizada, observou-se que dos seis clubes que apresentaram suas demonstrações, somente três deles apresentaram as Notas Explicativas, dois clubes apresentaram apenas o Balanço Patrimonial e a Demonstração do Resultado do Exercício, revelando que os clubes catarinenses precisam melhorar a evidenciação e a apresentação de suas Demonstrações Contábeis, a fim de não prejudicar a avaliação de seus resultados e dar mais credibilidade aos seus gestores. 
Na comparação com os resultados obtidos neste estudo aos resultados do estudo de Souza (2013), revelou-se um índice de conformidade das Demonstrações Contábeis com a legislação vigente de 51,82\% em nível estadual contra 52,43\% em nível nacional. Apenas em nível estadual, nas análises individualizadas realizadas nos seis clubes, pode-se constatar que há clubes participantes da elite do Campeonato Catarinense que estão aquém das exigências da legislação contábil vigente, casos como Hermann Aichinger e Metropolitano, que não estão em conformidade em nenhum dos itens estudados.

Há outros clubes que mostraram considerável avanço, como nos casos de Figueirense e Avaí, que na pesquisa realizada em 2011 por Souza (2013), tiveram média entre 58\% a 66\% e em 2012 aumentaram essa média para $81 \%$ a $91 \%$, respectivamente, ficando próximos da conformidade.

Os resultados indicaram que é necessário mais atenção e responsabilidade por parte dos gestores esportivos catarinenses e principalmente dos profissionais de contabilidade desses clubes para que não somente um ou dois estejam próximos da conformidade, mas sim, todos os clubes catarinenses passem a cumprir as exigências estabelecidas pela Lei e tornem-se referência no cenário nacional.

Como recomendações a futuras pesquisas relacionadas a essa área, sugere-se a realização de um comparativo com o nível de adequação à legislação de outros ramos de atividades desportivas e; realização de uma análise entre todos os estados do Brasil, analisando-se os clubes profissionais de futebol de cada Estado.

\section{REFERÊNCIAS}

AVAI FUTEBOL CLUBE. O clube: títulos. Disponível em: $<$ http://avai.com.br/oclube/titulos/>. Acesso em: 29 set. 2013.

BRASIL. LEI 6.354 de 02 de Setembro de 1976. Relações de trabalho do atleta profissional de futebol e dá outras providências. Disponível em: $<$ http://www.cbc.esp.br/stjd/Legislacao/lei_6354_76.pdf>. Acesso em: 17 out. 2013.

.LEI 9.615 de 24 de Março de 1998. Institui normas gerais sobre desporto e dá outras providências. Disponível em: $<$ http://www.planalto.gov.br/ccivil_03/leis/19615consol.htm>. Acesso em: 10 out. 2013.

. LEI 10.672 de 15 de Maio de 2003. Altera dispositivos da Lei 9.615, de 24 de Março de 1998. Disponível em: <http://www.planalto.gov.br/ccivil_03/leis/2003/110.672.htm>. Acesso em: 16 out. 2013.

. LEI 12.395 de 16 de Março de 2011. Altera as leis 9.615, de 24 de Março de 1998, que institui normas gerais sobre desporto, e 10,891, de 09 de Julho de 2004, que institui a BolsaAtleta; cria os Programas Atleta Pódio e Cidade Esportiva; Revoga a lei 6.354, de 02 de Setembro de 1976. Disponível em: <http://www.planalto.gov.br/ccivil_03/_ato20112014/2011/lei/112395.htm>. Acesso em: 15 out. 2013.

CÁS, Danilo da. Manual teórico-prático para elaboração metodológica de trabalhos acadêmicos. São Paulo: Jubela Livros, 2008.

Clube Atletico HERMANN AiCHINGER. Nossa história. Disponível em: $<$ http://www.atleticoha.com.br/historia.php>. Acesso em: 15 out. 2013.

Clube ATLETiCO METROPOlitano. História. Disponível em: $<\mathrm{http}$ ://www.metropolitano.net/?pag=historia $>$. Acesso em: 15 out. 2013. 
CONFEDERAÇÃO BRASILEIRA DE FUTEBOL. Competições. Disponível em:<http://www. http://www.cbf.com.br/Competicoes/>.Acesso em: 29 set. 2013.

CONSELHO FEDERAL DE CONTABILIDADE. NBC ITG 2003. Entidade Desportiva Profissional. Disponível em: $<$ http://www.cosif.com.br/mostra.asp?arquivo=nbc-itg-2003 $>$. Acesso em: 30 set. 2013.

Disponível

Resolução $\mathbf{n}^{0} \mathbf{1 . 0 0 5}$ de 04 de Setembro de 2004. Aprova a NBC $\mathrm{T}$ 10.13. http://www.crcsp.org.br/portal_novo/legislacao_contabil/resolucoes/Res1005.htm>. Acesso em: 30 set. 2013.

.Resolução no 1.429, de 25 de Janeiro de 2013. Aprova a ITG 2003. Disponível em: <http://www.normaslegais.com.br/legislacao/resolucao-cfc-1429-2013.htm>. Acesso em: 30 set. 2013.

CRICIUMA ESPORTE CLUBE. Conquistas. Disponível em: $<$ http://www.criciumaec.com.br/conquistas>.Acesso em: 29 set. 2013.

FEDERAÇÃO CATARINENSE DE FUTEBOL. História. Disponível em: <http:// http://www.fcf.com.br/federacao/>. Acesso em: 29 set. 2013.

FIGUEIRENSE FUTEBOL CLUBE. História. Disponível em: $<$ http://www.figueirense.com.br/o-clube/historia $>$. Acesso em: 15 out. 2013.

GIL, Antônio Carlos. Métodos e técnicas de pesquisa social. 5. ed. São Paulo: Atlas, 1999. JOINVILLE ESPORTE CLUBE. História. Disponível em: <http://jec.com.br/historia/>. Acesso em: 16 out. 2013.

NORMAS BRASILERIAS DE CONTABILIDADE. Disponível em: $<$ http://www.cfc.org.br/uparq/Normas_Brasileiras_de_Contabilidade.pdf $>$. Acesso em: 01 out. 2013.

NBC ITG 2003. Entidade Desportiva Profissional. Disponível em: <http://201.33.22.153/boletins/boletim410/itg2003.html>. Acesso em: 27 out 2013.

NBC T 10.13. Dos aspectos contábeis específicos em entidades desportivas profissionais. Disponível em: $<$ http://www.cfc.org.br/uparq/Normas_Brasileiras_de_Contabilidade.pdf $>$. Acesso em: 24. jun. 2012.

PRONI, Marcelo Weishaupt. A metamorfose do futebol. São Paulo: UNICAMP, 2000.

RAUPP, Fabiano Maury; BEUREN, Ilse Maria. Metodologia da pesquisa aplicável às ciências sociais. In: BEUREN, Ilse Maria. Como elaborar trabalhos monográficos em contabilidade: teoria e prática. São Paulo: Atlas, 2003.

SOUZA, Rafael Jaime. Demonstrações Contábeis de Clubes de Futebol do Brasil: uma análise da conformidade à legislação vigente [trabalho de conclusão de curso]. Florianópolis: Universidade Federal de Santa Catarina, Curso de Ciências Contábeis, Departamento de Ciências Contábeis; 2013. 